\title{
Job Crafting, Work Engagement, Burnout: Mediating Role of Self- Efficacy
}

\author{
Eva Rošková, Lucia Faragová \\ Faculty of Arts, Comenius University in Bratislava, Department of Psychology, Gondova 2, 81499 Bratislava, Slovak
} Republic

Based on the Job Demands-Resources model (JD-R), the aim of this study was to verify work engagement and burnout prediction models in relation to self-efficacy and the following four job crafting strategies: increasing structural job resources, increasing challenging job demands, increasing social job resources, and decreasing hindering job demands. Data was obtained by using questionnaires. The sample comprised 178 employed participants between 20 and 58 years of age. The results indicated that crafting challenging demands (e.g., seeking extra tasks) and social job resources (e.g., asking for feedback on job performance) was positively associated with work engagement. Behavioral strategies connected with the avoidance of difficulties at work (decreasing hindering job demands), associated with younger age of employees in managerial positions, significantly contributed to burnout. Self-efficacy as a personal source partially mediated the relationship between increasing challenging job demands and work engagement. Participants in managerial positions indicated a higher level of job crafting, work engagement, and self-efficacy as opposed to individual contributors. The results of the study are practically applicable in organizations in the form of stimulations, management, and the support of those job crafting strategies that contribute to benefits on an individual and organizational level.

Key words: job crafting, self-efficacy, engagement, burnout, JD-R model

\section{Introduction}

Job crafting is a specific form of proactive work behavior that involves employees actively changing the (perceived) characteristics of their jobs (Tims \& Bakker, 2010; Wrzesniewski \& Dutton, 2001). As job crafting is initiated by the employees themselves, it has been described as an individualized, bottom-up, and proactive approach to job re-design compared to top-down and "one-size-fits-all" approaches that are initiated by an organization (Demerouti \& Bakker, 2014; Parker, 2014; Parker \& Ohly, 2008).

Wrzesniewski and Dutton (2001) define job crafting as "physical and cognitive changes done by individuals in their work tasks and relations" (p. 179), whereby these changes are initiated and carried out in a "bottom-up" manner. Crafting work tasks involves changing a set of formal prescribed duties; such as adding or cancelling tasks; changing the nature of tasks; and changing how much time, energy,

Correspondence concerning this article should be addressed to Eva Rošková, Faculty of Arts, Comenius University in Bratislava, Department of Psychology, Gondova 2, 81499 Bratislava, Slovak Republic. E-mail: eva.roskova@uniba.sk ORCID https://orcid.org/0000-0002-1338-562X

Received August 2, 2019

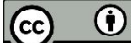


and attention an individual devotes to different tasks. Relationship crafting involves changing how, when, and with whom individuals cooperate, also reflecting the quality and number of interactions with other colleagues (Berg, Dutton, \& Wrzesniewski, 2008).

Employees, therefore, craft their work to create more motivating conditions and control it, confirm its meaningfulness, shape their working identity, and strengthen their work motivation. In addition to the reasons given above, whether or not an individual performs job crafting depends on the person-job fit. It is important to reflect on two aspects of that compliance: a) the match between individual knowledge, skills, and abilities in relation to the job requirements; and $b$ ) the correspondence between the needs and desires of the individual and their employment role. If all the factors are in balance, then the employee has a good "compliance" experience with the job. However, if they are not in balance, there is a misfit and disharmony, which can lead to job crafting that will help correct this relationship (Tims \& Bakker, 2010; Tims, Derks, \& Bakker, 2016).

Tims and Bakker (2010) theoretically framed job crafting in the context of the Job DemandsResources (JD-R) model, which is a comprehensive theoretical framework for understanding how job design elements influence occupational well-being and work performance. The model describes how job demands and resources influence motivation enhancing (e.g., work engagement) and strain-enhancing (e.g., exhaustion) processes and work performance.

Job demands encompass work characteristics that, if they exceed the adaptive capabilities of employees, can potentially lead to stress, strain, exertion, and burnout. Specifically, these include the physical, social, and organizational aspects of work (e.g., the amount of time to do tasks/time pressure, the amount of work, contact with people, and the physical environment) that require continuous physical or mental effort. Job resources encompass the physical, psychological, social, and organizational aspects of work that help to achieve work goals; reduce job demands; promote personal growth, learning, and development; and activate work motivation. Job resources are the main initiators of engagement and resulting performance of employees. Accordingly, job crafting serves as an important link between work motivation and the cultivation of job and personal resources that in turn help increase the person-job fit (Bakker \& Demerouti, 2017).

Based upon a theory presented by Tims and Bakker (2010), Tims et al. (2012) suggested that job crafting consists of four dimensions: increasing structural job resources includes performing behaviors that aim to increase the autonomy, skill variety, and other motivational characteristics of the job; increasing social job resources entails asking for feedback, advice, and support from supervisors and colleagues; increasing challenging job demands involves performing behaviors, such as asking for more responsibilities; and decreasing hindering job demands entails performing behaviors that aim to minimize physical, cognitive, and emotional demands, such as reducing one's workload and work-family conflict. To operationalize job crafting in terms of the JD-R model, Tims, Bakker, and Derks (2012) published a widely-used job crafting scale designed to measure job crafting.

The JD-R model assumes the existence of two basic processes that explain the relationship with work engagement and burnout (Bakker \& Demerouti, 2007; Schaufeli \& Bakker, 2004a). Firstly, job demands activate the energy depletion process, resulting in increased employee efforts to meet these demands or requirements. When employees encounter job demands, they often resort to different compensation strategies in order to maintain adequate work performance. However, in the long-term perspective, these strategies become ineffective and deplete the mental and physical reserves of employees, which in turn leads to burnout (Trépanier, Austin, Forest, \& Vallerand, 2014). On the other hand, job resources activate the motivation process. These resources support employee motivation and work engagement as they help them achieve their goals; promote their growth, edu- 
cation and development; satisfy their need for autonomy; and increase their willingness to invest effort into work tasks (Demerouti et al., 2001).

Tims, Bakker, and Derks (2012) report that job resources reinforce work engagement, employee motivation and energy, and subsequent positive organizational outcomes. Job resources also act as balancers of the negative effects of job requirements and can lead to occupational engagement even if job demands are high. For work motivation, it is very important to experience an appropriate level of challenging job demands to stimulate employees to develop their skills or set more ambitious goals for themselves. More demanding job requirements allow the acquisition of valuable experience, which can lead to higher satisfaction and self-efficacy (Gorgievski \& Hobfoll, 2008). Macey and Schneider (2008) say that challenging situations encourage work engagement if employees believe that their time and energy investment will be meaningfully rewarded. In a metaanalytical study, Crawford, LePine, and Rich (2010) document the positive relationship of challenging job demands with work engagement even when these have been assessed as stressful. On the contrary, demands that were considered to be hindering by employees correlated negatively with work engagement.

In addition, previous studies revealed that increasing social and structural job resources and increasing challenging job demands were negatively associated with burnout and boredom at work (Tims, Bakker, \& Derks, 2012; Van Hooff \& Van Hooft, 2014). These findings are consistent with the Conservation of Resources Theory (Hobfoll, 1989), which suggests that stress arises from inadequate job resources and leads to burnout. Individuals with a greater supply of job resources are more likely to cope with job demands whereas individuals with fewer resources are increasingly tense, which may lead to burnout. On the other hand, it was found that hindering job demands are linked to negative aspects of employee mental health such as burnout (Schaufeli,
Bakker, \& Van Rhenen, 2009; LePine Podsakoff, \& LePine, 2005).

Previous studies on the JD-R model focused on job characteristics, leading to a neglect of personal resources. This is despite the fact that personal resources play a comparable role in occupational life: they lead to increased employee motivation and engagement, are related to stress resistance, and have positive effects on emotional and physical well-being (Schaufeli \& Bakker, 2004a). Personal resources such as self-esteem, optimism, and self-efficacy are positively related to work engagement (Xanthopoulou, Bakker, Demerouti, \& Schaufeli, 2007; 2009). On the contrary, employees with a low level of selfefficacy have pessimistic ideas about their future success and personal development, which can lead to burnout. Research in this area has shown that self-efficacy acts as a source of prevention from the negative consequences of an excessive and long-term work load (Blecharz, Luszczynska, Scholz, Schwarzer, Siekanska, \& Cieslak, 2014), stimulating work-related recovery from stress and helping employees adapt to changes in an organization (Jimmieson, Terry, \& Callan, 2004).

Self-efficacy and personality proactivity are among the personality traits that play an important role in job crafting. Tims and Bakker (2010) report that people with a proactive personality are more likely to engage in job crafting willingly: they take the initiative to improve their current work conditions, identify opportunities for change, and start and persevere until they achieve a meaningful change.

In their study, Xanthopolou et al. (2007) found that self-efficacy, self-esteem, and optimism partly served as mediators between job resources and work engagement. Similarly, Luthans, Avey, Avolio, Norman, and Combs (2006) documented that a work resource-rich environment activates employees' psychological capital (i.e., hope, optimism, efficiency, and resilience), which in turn can lead to profits and positive results at work. Huang, Wang, and You (2016) have further shown that selfesteem and optimism are important media- 
tors in the relationship between work overload and exhaustion.

\section{The Current Study}

Current research, based on Tims and Bakker's (2010) conceptualization of job crafting, has adopted different operationalizations of this construct. Petrou, Demerouti, Peeters, Schaufeli, and Hetland (2012) merged two dimensions of their conceptualization - increasing structural and social job resources - into one increasing job resources dimension and differentiated between only three types of job crafting. Similarly, Nielsen and Abildgaard (2012) identified two factors: decreasing social job demands and increasing quantitative job demands. Because there are a number of alternative operationalizations of job crafting, the first goal of the present study was to examine the structure of the latent factors of the job crafting scale to see whether they could be meaningfully distinguished from each other. Then the relationships between dimensionspecific forms of job crafting, work engagement, burnout, and self-efficacy were more closely examined. Several researchers have examined these relationships (Crawford, LePine, \& Rich, 2010; Hansez \& Chmiel, 2010; Tims, Bakker, \& Derks, 2012; Tims, Bakker, \& Derks, 2013; Brauchli et al., 2013; Van; Hooff, \& Van Hooft, 2014), but self-efficacy as a personal resource has often been neglected. Employees who believe in their self-efficacy choose more demanding tasks, set higher goals, put more effort into their performance, and are more persistent, compared to employees who have a lower level of self-efficacy (Lunenburg, 2011). As mentioned in the Introduction, personal resources play an important role in relation to burnout and engagement. They have a comparable role to work resources as they lead to increased employee motivation and engagement (Schaufeli \& Bakker, 2004a; Xanthopolou et al., 2007; Xanthopolou et al., 2009; Huang, Wang, \& You, 2016).

The lack of literature led the present authors to the question of whether position level (managerial and non-managerial) contributes to job crafting strategies as a distal antecedent. Karasek (1979) introduced the concept of active jobs, which denotes professions with high demands and a high level of control. These professions encourage employees to actively learn, and they motivate them to new patterns of behavior. Based on this concept, managerial positions represent active jobs with higher autonomy and control, albeit with certain demands. According to the 2016 Employee Engagement Trends (Hackbarth, Harris, \& Wright, 2016), engagement increases as employees gain higher-level positions within a company, which might be strengthened in a "feedback loop" level of job crafting (Baker, 2011). In the present study, the aim was to test whether managerial positions increase the likelihood of job crafting strategies through searching for resources and challenges.

Research regarding age and gender differences in job crafting is somewhat equivocal. For example, Petrou, Demerouti, and Xanthopoulou (2016) identified a higher level of job crafting for men, whereas Van Hoof and Van Hooft (2014) documented the opposite. Based upon action regulation theory, it can be argued that older and more experienced employees (i.e., relative to younger and less experienced ones) are more likely to have developed cognitive routines in their work that might lower behavioral changes like job crafting (Zacher, Hacker, \& Frese, 2016). On the other hand, several studies document a higher level of work engagement for older employees (e.g., Najung \& Seung-Wan, 2017) and a positive influence of work engagement (in the "feedback loop") on job crafting strategies (Baker, 2011). For that reason, there are no specific predictions made on age and gender characteristics and job crafting; however, it is nonetheless useful to understand the nature of such relationships in further research.

Following the abovementioned findings, this study assumes that:

1. self-efficacy will be positively related to increasing structural and social resources, thus increasing challenging job demands

2. self-efficacy will also act as a mediator between job crafting dimensions (increasing 
structural and social resources and increasing challenging job demands) and work engagement

3. increasing structural and social job resources, and increasing the challenging job demands, will predict work engagement, whereas reducing the hindering demands will predict burnout

4. managerial positions will strengthen job crafting strategies

\section{Methods}

\section{Participants and Procedure}

Data was collected using an online questionnaire through social networks and with voluntary participation. A minimum inclusion criterion was used; selected participants indicated that they were in full-time employment for a fixed or indefinite term. Part-time workers and freelancers were excluded from the sample. In total, 178 employees participated in the study. More than half of the sample was female $(59 \%)$, the average age of the participants was $33.3(S D=8.45)$ years, and $35.4 \%$ of participants were managers. The educational level of the participants was relatively high: almost $78 \%$ of the participants reported having a bachelor's degree or a higher qualification. Thirty-seven percent of employees worked in a medium-sized organization (51-500 employees), $37 \%$ in a large one (over 501 employees), and $26 \%$ indicated they were employed in a small organization (up to 50 employees). Participants were provided with an informed consent sheet that included information on the purpose of the research, their right to anonymity, and a reassurance that the results would be used exclusively for research purposes.

\section{Measures}

Four self-reporting measures and scales were administered in the form of online questionnaires. Two independent translations into Slovak (and then back into English) were done of three questionnaires (measuring work engagement, job crafting, and burnout) to be used in the study, and the final versions were agreed upon after mutual consent between two translators. The self-efficacy questionnaire was adapted to the Slovak population, and there was no need to translate it.

Work engagement was measured with the short nine-item version of the Dutch Utrecht Work Engagement Scale (UWES; Schaufeli, Bakker, \& Salanova, 2006) measuring the three dimensions of engagement - vigor, dedication, and absorption. An example item is: "At work, my colleague feels bursting with energy". A 7-point scale was used with answers ranging from 0 (never) to 6 (always). De Bruin and Henn (2013) provided evidence for the presence of a general factor and that the interpretation of a total score is justified and preferable. Internal consistency confirmed the strong reliability $(\alpha=.95)$.

Job crafting was measured with the 21 items of the job crafting scale (Tims, Bakker, \& Derks, 2013). The scale measures four basic dimensions of job crafting: increasing structural job resources (e.g., "I'm trying to improve my skills"); increasing social job resources (e.g., "I ask my supervisor to direct me"); decreasing hindering job demands (e.g., "I try to make my work less emotionally intense"); and increasing challenging job demands (e.g., "When an interesting project emerges, I volunteer as a collaborator"). Participants responded on a five-point Likert scale $(1=$ never, $5=$ frequently). Cronbach's alphas were all above the recommended .70 .

The Bergen Burnout Inventory (BBI-15) (Näätänen, Aro, Matthiesen, \& Salmela-Aro, 2003) was used to measure burnout level. BBI15 measures the three dimensions of burnout: exhaustion (e.g., "I often sleep poorly because of the situation at work"), cynicism (e.g., "I feel depressed and think about leaving my current work"), and inadequacy (e.g., "I often question the value of my work"). Participants responded on a six-point Likert scale $(1=$ totally disagree, $6=$ totally agree). The score can be calculated separately for each dimension or as a total burnout score. The measured reliability coefficient for the whole scale was high with an alpha value $=.90$ 
The General Self-Efficacy Scale (GSE) (Košč, Heftyová, Schwarzer, \& Jerusalem, 1993) was used to measure the level of self-efficacy. The scale contains ten statements (e.g., "I can find a way out of almost every problem if I make the necessary effort"), and participants answered to what extent the statement applied to them on a four-point Likert scale $(1=$ not at all true for me, $4=$ totally true for me). The value of the reliability coefficient alpha $=.86$.

Demographic variables. The questionnaire provided to the participants also asked them to indicate their position level (managerial/nonmanagerial), level of education, type of contract, size of organization, gender, and age for use as demographic variables. In line with the goal of the study, only the variables of position level, gender, and age were included.

\section{Statistical Analyses and Procedure}

Before completing the statistical analyses and the dimensionality, the latent structure of the 21 items of the job crafting scale was performed. The factor analysis maximum likelihood was used to examine whether four factors of the job crafting scale could be meaningfully distinguished from each other. As a criterion to retain factors, those factors that had an eigenvalue higher than 1 were retained. The loadings in the matrix were meant to be higher than 0.30 in order to decide whether an item was acceptable for the component. A correlation analysis, hierarchical regression analysis, and mediation analysis were conducted in order to investigate how demographic variables, self-efficacy, job crafting dimensions, engagement, and burnout are connected. Two separate hierarchical regression analyses were conducted on each outcome variable (engagement and burnout) in three steps. Previous studies (e.g., Petrou et. al., 2016; Najung \& Seung-Wan, 2017; Hackbarth, Harris, \& Wright, 2016) linked gender differences (i.e., being a woman), age differences (i.e., older employees), and position level (i.e., managerial) to work outcomes, which emphasizes the importance of controlling the potential effect of those variables in the prediction models.
Hence, age, gender, and position level were entered into the model at Step 1. Given the prior findings between self-efficacy and work outcomes, self-efficacy was entered at Step 2 and behavioral job crafting strategies were entered at Step 3. A mediation analysis was used to verify the role of self-efficacy as a mediator between job crafting dimensions, engagement, and burnout. First, the requested conditions that had to be met were tested before the mediation analysis (the relationship between the independent variable and the mediator, the relationship between the independent variable and the dependent variable, and the relationship between the mediator and the dependent variable). The process tool in the SPSS statistical package by Andrew F. Hayes (2013) was used for the mediation analysis. Bootstrapped standard errors were calculated for path coefficients. The indirect effect was also tested using the bootstrapping procedure on 10,000 samples. The completely standardized indirect effect (Preacher \& Kelley, 2011) was used as a measure of effect size.

\section{Results}

First, the factor structure of the job crafting scale using the factor analysis (maximum likelihood) was examined. An examination of the eigenvalues and the scree plot reflected a four-factor solution in the line with the original instrument. Five items with loadings smaller than 0.30 were removed: "If there are new developments, I am one of the first to learn about them and try them out"; "I try to make my work more challenging by examining the underlying relationships between aspects of my job" (from Increasing Challenging Job Demands); "I decide on my own how I do things" (from Increasing Structural Job Resources); "I look to my supervisor for inspiration" (from Increasing Social Job Resources); and "I make sure that my work is mentally less intense" (from Decreasing Hindering Job Demands).

Following this, a factor analysis was conducted with a maximum likelihood on the remaining sixteen items to identify the final solution. An additional factor analysis showed a 
$\mathrm{KMO}$-index of 0.792 , and a significant $(p=0.000)$ Bartlett's test of sphericity. The pattern matrix documented that there should be a distinction between four dimensions of the scale, accounting for $48 \%$ of the variance. The findings were the following for the number of the items for each factor: the Increasing Structural Job Resources factor was saturated with three items, the Increasing Challenging Job Demands factor had four items, the Decreasing Hindering Job Demands consisted of five items, and four items were identified for the Increasing Social Job
Resources factor. In addition, to test the reliability of all scales, Cronbach's alpha $(\alpha)$ coefficient was used and was derived from the reliability analysis. The factor loadings, items, means, standard deviations, and Cronbach's alphas are shown in Table 1.

Following this, Spearman's correlation analysis on testing variables was performed. The means, standard deviations for the studied variables, reliability coefficients for the scales used, and the correlation matrix are presented in Table 2.

Table 1 Items, means, standard deviations, Cronbach's alphas, and factor loadings of the job crafting scale $(N=178)$

\begin{tabular}{|c|c|c|c|c|c|c|c|c|}
\hline & \multirow[b]{2}{*}{ Item wording } & \multirow[b]{2}{*}{ Mean } & \multirow[b]{2}{*}{$S D$} & \multirow[b]{2}{*}{ Alpha } & \multicolumn{4}{|c|}{ Factor } \\
\hline & & & & & 1 & 2 & 3 & 4 \\
\hline & Increasing structural job resources & & & .84 & & & & \\
\hline 1 & I try to develop myself professionally & 4.24 & 0.85 & & .79 & & & \\
\hline 2 & I try to develop my capabilities & 4.11 & 0.92 & & .74 & & & \\
\hline 3 & I try to learn new things at work & 4.23 & 0.86 & & .63 & & & \\
\hline & Increasing challenging job demands & & & .78 & & & & \\
\hline 4 & $\begin{array}{l}\text { When there is not much to do at work, I see it as a } \\
\text { chance to start new projects }\end{array}$ & 3.44 & 1.09 & & & .77 & & \\
\hline 5 & $\begin{array}{l}\text { I regularly take on extra tasks even though I do not } \\
\text { receive extra salary for them }\end{array}$ & 3.52 & 1.18 & & & .69 & & \\
\hline 6 & I make sure that I use my capacities to the fullest & 3.59 & 1.01 & & & .52 & & \\
\hline 7 & $\begin{array}{l}\text { When an interesting project comes along, I offer } \\
\text { myself proactively as project co-worker }\end{array}$ & 3.26 & 1.01 & & & .46 & & \\
\hline & Decreasing hindering job demands & & & .74 & & & & \\
\hline 8 & $\begin{array}{l}\text { I manage my work so that I try to minimize contact } \\
\text { with people whose problems affect me emotionally }\end{array}$ & 3.12 & 1.14 & & & & .83 & \\
\hline 9 & $\begin{array}{l}\text { I organize my work so as to minimize contact with } \\
\text { people whose expectations are unrealistic }\end{array}$ & 3.00 & 1.25 & & & & .70 & \\
\hline 10 & $\begin{array}{l}\text { I organize my work in such a way to make sure that } \\
\text { I do not have to concentrate for too long a period at } \\
\text { once }\end{array}$ & 3.01 & 1.15 & & & & .48 & \\
\hline 11 & $\begin{array}{l}\text { I try to ensure that I do not have to make many } \\
\text { difficult decisions at work }\end{array}$ & 2.59 & 1.09 & & & & .46 & \\
\hline 12 & $\begin{array}{l}\text { I try to ensure that my work is emotionally less } \\
\text { intense }\end{array}$ & 3.05 & 1.09 & & & & .38 & \\
\hline & Increasing social job resources & & & .72 & & & & \\
\hline 13 & $\begin{array}{l}\text { I ask whether my supervisor is satisfied with my } \\
\text { work }\end{array}$ & 2.66 & 1.23 & & & & & .86 \\
\hline 14 & I ask others for feedback on my job performance & 3.12 & 1.14 & & & & & .59 \\
\hline 15 & I ask colleagues for advice & 3.37 & 0.95 & & & & & .42 \\
\hline 16 & I ask my supervisor to coach me & 2.58 & 1.05 & & & & & .42 \\
\hline
\end{tabular}




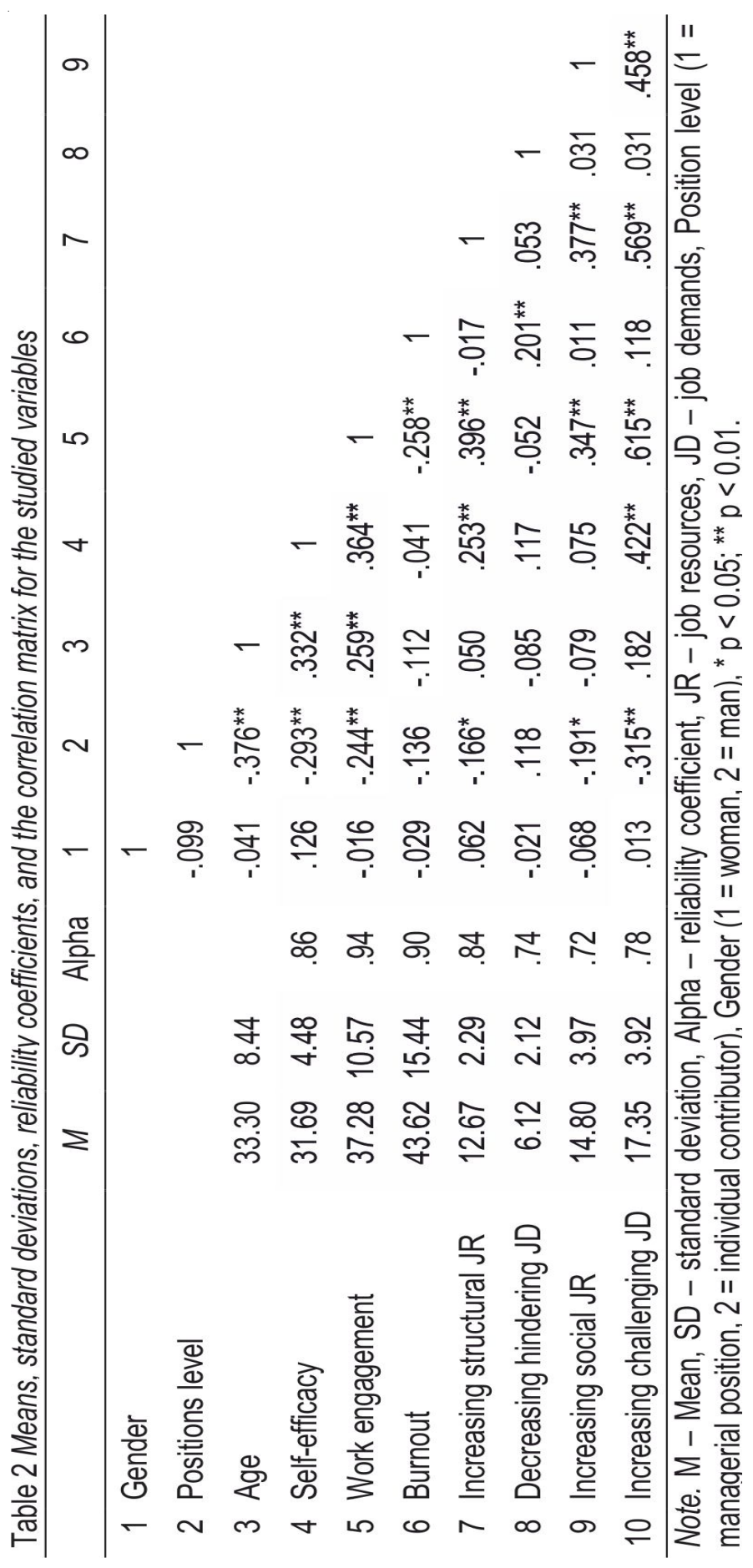


The expected positive relationship between job resources (social and structural) and work engagement was confirmed $(r=0.396, p=$ $0.000 ; r=0.347, p=0.000)$. Apparently, if employees have the opportunity to increase their social and structural resources, this strongly supports their work engagement. A similar principle existed for the positive relationship between increasing challenging job demands and work engagement $(r=0.615 ; p=0.000)$. Furthermore, the findings showed a significant positive correlation between decreasing hindering job demands and burnout $(r=0.201$; $p=0.001)$. The relationships of the variables regarding increasing job resources (both social and structural) and increasing challenging job demands and burnout were non-significant (Table 2).

Self-efficacy as a personal resource was significantly related to work engagement $(r=$ $0.364 ; p=0.000)$, participating in the increase of structural resources $(r=0.253 ; p=0.001)$ and in increasing challenging job demands $(r=0.422 ; p=0.000)$. Self-efficacy does not significantly contribute to an increase in social resources $(r=0.075)$ or to decreasing hindering job demands $(r=0.117)$ (Table 2).

As expected, participants in managerial positions indicated a higher level of job crafting in the area of increasing structural resources $(r=-0.166 ; p=0.027)$ and increasing chal- lenging job demands $(r=-0.315 ; p=0.000)$ as opposed to individual contributors. These participants also showed higher levels of work engagement and self-efficacy (Table 2). In terms of background variables (age and gender), the results indicated only weak and insignificant connections with job crafting strategies; a higher level of self-efficacy $(r=0.332$; $p=0.000)$ and engagement $(r=0.259 ; p=$ 0.000 ) was shown for older employees.

Two separate hierarchical regression analyses were conducted to evaluate prediction models on each of the outcome variables (engagement and burnout) in three steps. Age, gender, and position level were entered into the model at Step 1, self-efficacy was entered at Step 2, and behavioral and job crafting strategies were entered at Step 3. The models and results are presented in Table 3 .

In the regression model for engagement, independent variables accounted for $39.6 \%$ of the variability (Table 3 ). Significant predictors for work engagement identified: increasing challenging job demands $(\beta=0.46, p=0.000)$, increasing social job resources $(\beta=0.17, p=$ $0.022)$, and age $(\beta=0.15, p=0.031$. Other variables that exhibited significant correlation with work engagement (Table 2) - self-efficacy, increasing structural job resource and position level - lost their predictive power in mutual linear combination. Higher age, imple-

Table 3 Hierarchical regression analyses on engagement and burnout

\begin{tabular}{|c|c|c|c|c|c|c|c|c|c|c|}
\hline \multirow[b]{2}{*}{ Step } & \multicolumn{2}{|c|}{ Overall model } & \multicolumn{8}{|c|}{ Predictors/Beta } \\
\hline & $R^{2}$ & $F$ & gender & age & position & $\begin{array}{c}\text { Self- } \\
\text { efficacy }\end{array}$ & IStrJR & DHJD & ISocJR & ICHJD \\
\hline \multicolumn{11}{|c|}{ Engagement } \\
\hline 1. & .08 & $5.09^{* *}$ & .01 & $.17^{*}$ & $-.18^{* *}$ & & & & & \\
\hline 2. & .12 & $5.93^{* *}$ & -.03 & .13 & -.14 & $.21^{*}$ & & & & \\
\hline 3. & .39 & $13.87^{* *}$ & .02 & $.15^{*}$ & .04 & .12 & .01 & -.08 & $.17^{*}$ & $.46^{\star *}$ \\
\hline \multicolumn{11}{|c|}{ Burnout } \\
\hline 1. & .04 & 2.59 & -.07 & $-.18^{\star *}$ & $-.18^{* *}$ & & & & & \\
\hline 2. & .04 & 1.96 & -.07 & $-.17^{\star}$ & $-.18^{*}$ & -.02 & & & & \\
\hline 3. & .14 & $3.29^{* *}$ & -.07 & $-.19^{*}$ & $-.19^{*}$ & -.09 & -.01 & $.24^{* *}$ & -.16 & $.21^{*}$ \\
\hline
\end{tabular}

Note. IStrJR = Increasing structural job resources, DHSJD = Decreasing hindering job demands, ISocJR = Increasing social job resources, ICHJD = Increasing challenging job demands; gender $\left(1=\right.$ female, 2 = male), position $\left(1=\right.$ managerial, 2 = non- managerial); ${ }^{*} p<0.05,{ }^{* *} p<0.01$. 
menting strategies to increase social job resources (working with colleagues), and challenging job demands (workload and cognitive demands) contribute to work engagement.

Regarding the prediction model for burnout regression, the analysis (Table 3 ) showed that the combination of inserted variables accounted for $14 \%$ of variability. A combination of variables were identified as the strongest predictors of burnout: decreasing hindering job demands $(\beta=0.24, p=0.001)$, increasing challenging job demands $(\beta=0.21, p=0.041)$, position level $(\beta=-0.19, p=0.017)$, and age $(\beta=-0.19, p=0.017)$. Burnout is significantly contributed to by a combination of younger respondents in managerial positions, the implementation of strategies decreasing hindering demands (e.g., making difficult decisions), and increasing social job resources (e.g., asking feedback from supervisors and colleagues).

The assumption about the role of self-efficacy as a mediator in the relationship between job resources, job demands, and work engagement was tested by a mediation regression analysis using the Process tool in the SPSS statistical package by Andrew F. Hayes (2013). Requested conditions for mediation were met for testing two mediation models: 1) increasing challenging job demands-selfefficacy-work engagement-self-efficacy-work engagement and 2) increasing structural job resources-self-efficacy-work engagement. The aim of the mediation was to identify the size of the indirect effect (self-efficacy) by controlling the direct effect of a) increasing challenging job demands on work engagement and $b$ ) increasing structural job resources on work engagement.

Figure 1 shows that self-efficacy partly mediates the correlation between increasing challenging job demands and work engagement. The results documented that the increase in challenging job demands significantly predicts self-efficacy $(\beta=0.315, p=0.002)$, and selfefficacy significantly predicts work engagement $(\beta=1.489, p=0.000)$. Also, challenging job demands was a significant predictor of work engagement $(\beta=1.580, p=0.000)$.

After incorporating the mediator of self-efficacy into this relationship, the effect of challenging job demands on work engagement was partially reduced $(\beta=1.489, p=0.000)$, but the direct effect of increasing structural job resources on work engagement remained statistically significant. In practice, this means that self-efficacy as a personal resource contributes only minimally to the explicability of work engagement. The size of the resulting indirect effect (after mediator control) was ES $=0.0908$, $95 \% \mathrm{Cl}[0.019,0.2689]$ (Figure 1).

When testing the second mediation model (increasing structural job resources-self-efficacy-work engagement), the results showed no mediation effect between crafting structural job resources and work engagement via selfefficacy (Cl $[-0.012,0.493])$.

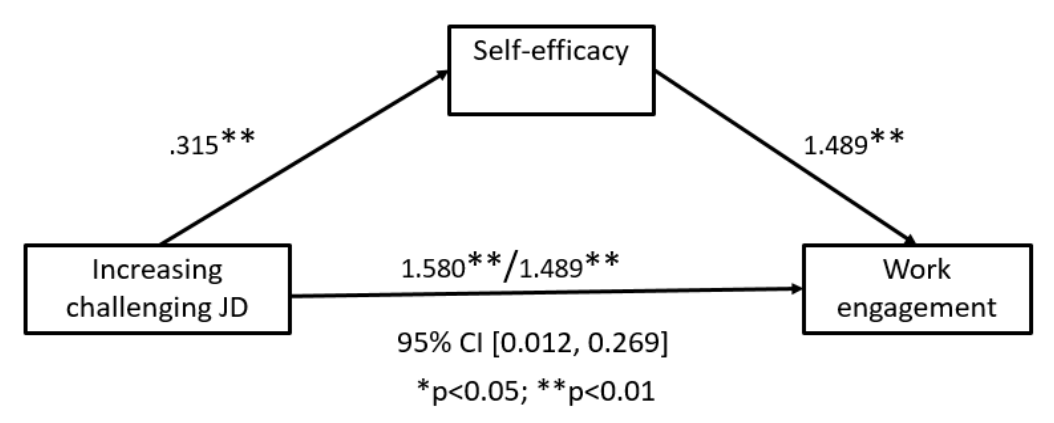

Figure 1 Mediation analysis: increasing challenging job demands-self-efficacy-work engagement 


\section{Discussion}

Based on Tims and Bakker's (2010) conceptualization of job crafting, the first aim of the study was to examine whether the four-factor structure of the job crafting scale could be replicated. The next aim was to test how personal resource self-efficacy contributes to job crafting strategies and how job crafting dimensions vary as a function for predicting different work outcomes (engagement and burnout). The relationship between managerial positions and job crafting strategies was also examined.

Using the factor analysis (maximum likelihood) to verify the latent structure of the job crafting scale, a four-factor solution was identified with some differences in the number of items and in the factor loadings when compared to the original instrument. Although the present results are consistent with the initial findings of Tims, Bakker, and Derks (2012), previous research has been ambiguous in the results (e.g., Petrou et al., 2012; Nielsen \& Abildgaard, 2012). For this reason, the present study sees the importance of contributing to this issue with the present results and confirms the number of dimensions of job crafting.

Findings concerning the relationship between self-efficacy and job crafting dimensions were partially as expected, but there were also some unexpected results. Research has shown that self-efficacy plays an important role in relation to working life as one of the personal resources. Respondents who showed a higher level of self-efficacy were more engaged at work and carried out job crafting at a much higher level, namely for structural job resources and challenging job demands. Decreasing hindering job demands and increasing social job resources had weak associations with self-efficacy. Rudolph, Katz, Lavigne, and Zacher (2017) in their study documented associations of self-efficacy with all of job crafring strategies except for decreasing hindering job demands. Explanation for our findings might be that employees with higher level of general self-efficacy direct more attention to "growth-oriented" job crafting behaviors than to decreasing hindering demands and "people-oriented" crafting strategies (e.g., communication, cooperation with colleagues). In addition, older people showed higher levels of self-efficacy and engagement. This may be due to the fact that older employees have more work experience, are more mature, and value their work. This can lead to more positive selfesteem and commitment to work.

In general, the results emphasize the importance of self-efficacy, which has often been neglected as a personal resource in research. It is important to say that personal resources are comparable to work resources, as they lead to increased employee motivation, performance, and engagement (Schaufeli \& Bakker, 2004a; Xanthopolou et al., 2007; Xanthopolou et al., 2009; Huang, Wang, \& You, 2016). Various research in this area has shown that self-efficacy acts as a source of prevention against the negative effects of excessive and long-term stress (Blecharz et al., 2014), stimulates recovery from work-related stress, and helps employees adapt to organizational changes (Jimmieson, Terry, \& Callan, 2004).

On the other hand, when incorporating selfefficacy into regression models, the abovementioned correlations did not work. Self-efficacy became a non-significant variable in work engagement prediction. The significant predictors in this relationship were increasing challenging job demands, age, and increasing social job resources. The combination of a higher age, strategies to increase social job resources (social support, working with colleagues), and challenging job demands (seeking new projects, taking on extra tasks) contributed to work engagement. In the other words, in case of "supportive environment" at work, behavioral strategies play a more important role in shaping positive work outcome (engagement) than personal resources (selfefficacy). Crawford et al. (2010) also found a positive correlation between challenging job demands and work engagement, even when these were assessed as stressful. In terms of the prediction of burnout, self-efficacy was com- 
paratively non-significant. A lower age, managerial position, decreasing hindering job demands, and increasing challenging job demands significantly contributed to burnout. It seems, age is one of the important predictors of an employee's well-being. Considering the so-called structural model (Maslach, Jackson, \& Leiter, 1996), responsibilities associated with managerial position, expected strategies in seeking new challenges in those positions, and strategies connected with regulation of the presence of specific demands (i.e., work overload, personal conflicts) together with younger age and the absence of specific resources (i.e., experience) can lead to long-term discomfort, uncertainty, and often burnout.

A study by Huang, Wang, and You (2016) has shown that personal resources, including selfefficacy, also act as mediators in the relationship between work conditions and outcomes (behavior and attitude). The present study tested the size of the indirect effect of self-efficacy by controlling the direct effect of increasing structural job resources on engagement and increasing challenging job demands on engagement. One finding was that self-efficacy partially explains the relationship between challenging job demands and work engagement. This result contradicts previous findings, which have shown that satisfaction is one of the personal resources that mediated the relationship between job demands and exhaustion and between job resources and energy (Van den Broeck et al., 2008). Previous studies only focused on verifying the relationships between job demands, job resources, and outcomes in general (Huang, Wang, \& You, 2016; Van den Broeck et al., 2008; Xanthopolou et al., 2007). This study focused in more detail on job resources and demands, examining social job resources and challenging job demands in relation to work engagement. There was an assumption that the differences in job resources and job demands ought to be taken into consideration in future research. As mentioned above, for some people time pressure can be perceived as a challenging job demand, whereas for others it is a hindering job demand.
Findings for job crafting and work engagement were largely as expected based upon theoretical considerations and consistent with meta-analytic findings for other forms of proactive behavior (Tornau \& Frese, 2015). The results of our study illustrate that job crafting in the area of increasing social, structural, and challenging job demands contributes positively to employee engagement and refers to the functioning of the motivational potential of the job resources that improve person-job fit which, in turn, positively impacts job attitudes, and occupational well-being.

Regarding the connection between the distal variable and job position (managerial and non-managerial), it was proposed that managerial positions would increase the likelihood of job crafting strategies through the search for resources and challenges. The present findings confirmed this expectation and showed that a managerial position was significantly associated with the job crafting dimensions of increasing structural and social job resources and increasing challenging job demands. The only job crafting dimension, where there were insignificant associations, was in decreasing hindering job demands. One explanation may be that in job crafting, employees voluntarily change their work themselves in a meaningful way. These characteristics distinguish job crafting from top-down approaches, whereby employees are checked by their supervisor as to how they should perform their work (Grant \& Parker, 2009). However, a problem may arise in working conditions where job crafting cannot be performed. Indeed, some jobs have a well-defined structure and require strict rules and procedures that are contrary to any attempt to change working conditions. Job crafting may be also affected by superiors who require work to be performed in a prescribed manner. On the other hand, managers are not usually under strict scrutiny and can do their jobs in the way they choose.

The above findings point to a greater significance of job resources and challenging job demands, compared to personal resources, in terms of both work engagement and burn- 
out; the personal resources in the presented research acted more as distal variables in relation to behavior (job crafting), attitudes (engagement), and experience (burnout) as opposed to proximal job resources. The fact that self-efficacy has been assessed as a general characteristic has contributed to the documented findings, thus, in the future there should be a focus on the specific and direct assessment of work self-efficacy. Also, specific job crafting dimensions are differentially associated with both antecedents and work outcomes. In particular, decreasing the hindering demands dimension appears to differ markedly from the other three job crafting dimensions, and this observation deserves further attention in future research.

In summary, the present study contributes to the enhanced understanding of the nature of the job crafting construct, its unique relationships between each job crafting dimension, and work outcomes (engagement and burnout). It investigated the role of individual difference (self-efficacy) and demographic characteristics (type of position) as antecedents of job crafting and mediators (self-efficacy) between dimensions of this proactive behavior and work outcomes (engagement and burnout).

\section{Limitations}

The present study took into account a number of limitations related to behavioral science research that may have influenced the presented results (Podsakoff, MacKenzie, Lee, \& Podsakoff, 2003). The research design was based solely on self-assessment methodology. The predictor and criterion variables were measured using the same tools (self-assessment Likert scales) at the same time and place, which could be a source of "false" covariance, independent of the content of the constructs themselves. The cross-sectional design of the research was another limiting factor; data was obtained only in one measurement. Job crafting is not an isolated and one-time affair; it is a continuous process influenced by the career path and context within which individuals perform their work and by changes to the conditions in which work is performed (Fried, Grant Levi, Hadani, \& Slowik, 2007). The presented measurements did not allow for a study of the reciprocity between job crafting variables and the work engagement presented by several studies. Another study limitation is the size of the sample and the non-random and occasional selection of participants. Furthermore, the sample was not representative of employees in Slovakia in terms of sample size, the uniform distribution of some of the studied variables, or economic segments. The participants were approached through social networks instead of directly, which could have resulted in the research participation of only those individuals, who are active users of social networks.

\section{Practical Implications}

Looking at job crafting and the implications based on the presented research, it is important to note that employees should have the opportunity to change their working conditions within their organization. Job crafting is a way that employees can change their lives at work and make a valuable contribution to their organization. Each employee is different, and it is very difficult to create optimal working conditions for each employee individually. This is why employees should be allowed to adjust their working conditions at their discretion, as this may affect their subsequent working behavior. Moreover, organizations and employers can invest in various programs designed to develop and improve personal resources. As one of the personal resources, self-efficacy can affect the way employees perceive job characteristics and help them overcome difficulties at work.

\section{Acknowledgement}

This research was carried out with the support of the Slovak grant agency VEGA, grant scheme VEGA 1/0273/18. 


\section{References}

Bakker, A. B., \& Demerouti, E. (2007). The job demands-resources model: State of the art. Journal of Managerial Psychology, 22(3), 309-328. https:/ /doi.org/10.1108/02683940710733115

Bakker, A. B., Schaufeli, W. B., Leiter, M. P., \& Taris, T W. (2008). Work engagement: An emerging concept in occupational health psychology. Work \& Stress, 22, 187-200.

Bakker, A. B. (2011). An evidence-based model of work engagement. Current Directions in Psychological Science, 20, 265-269. https://doi.org/ $10.1177 / 0963721411414534$

Bakker, A. B., \& Demerouti, E. (2014). Job demandsresources theory. In P. Y. Chen \& C.L. Cooper (Eds.), Work and wellbeing: $A$ complete reference guide (pp. 1-28). John Wiley \& Sons, New York.

Bakker, A. B., \& Demerouti, E. (2017). Job demandsresources theory: Taking stock and looking forward. Journal of Occupational Health Psychology, 22(3), 273-285. https://doi.org/10.1037/ ocp0000056

Baron, R. M., \& Kenny, D. A. (1986). The moderatormediator variable distinction in social psychological research: Conceptual, strategic, and statistical considerations. Journal of Personality and Social Psychology, 51(6), 1173-1182.

Berg, J. M., Dutton, J. E., \& Wrzesniewski, A. (2008). What is job crafting and why does it matter? Positive Organizational Scholarship, 1-8.

Blecharz, J., et al. (2014). Predicting performance and performance satisfaction: The role of mindfulness and beliefs about the ability to deal with social barriers in sport. Anxiety, Stress, \& Coping, 27, 270-287.

Brauchli, R., Schaufeli, W. B., Jenny, G. J., Füllemann, D., \& Bauer, F. G. (2013). Disentangling stability and change in job resources, job demands, and employee well-being: A three-wave study on the job-demands resources model. Journal of Vocational Behavior, 83, 117-129. https://doi.org/ 10.1016/j.jvb.2013.03.003

Costello, A. B., \& Osborne, J. W. (2005). Best practices in exploratory factor analysis: Four recommendations for getting the most from your analysis. Practical Assessment, Research, \& Evaluation, 10, 1-9.

Crawford, E. R., LePine, J. A., \& Rich, B. L. (2010). Linking job demands and resources to employee engagement and burnout: A theoretical extension and meta-analytic test. Journal of Applied Psychology, 95(5), 834-848. https://doi.org/10.1037/ a0019364
De Bruin, G. P., \& Henn, C. M. (2013). Dimensionality of the 9-item Utrecht Work Engagement Scale (UWES-9). Psychological Reports, 112, 788-799. https://doi.org/10.2466/01.03.PR0.112.3.788-799 Demerouti, E., \& Bakker, A. B. (2014). Job crafting. In M. C. W. Peeters, J. de Jonge \& T. W. Taris (Eds.), An Introduction to Contemporary Work Psychology. London, UK: Wiley.

Fried, Y., Grant, A., Levi, A., Hadani, M., \& Slowik, L. (2007). Job design in temporal context: A career dynamics perspective. Journal of Organizational Behavior, 28(7), 911-927.

Gorgievski, M. J., \& Hobfoll, S. E. (2008). "Work can burn us out or fire us up: Conservation of resources in burnout an engagement". In J. R. B. Halbesleben (Ed.), Handbook of Stress and Burnout in Health Care (pp. 7-22) Hauppauge, NY: Nova Science.

Hackbarth, N., Harris, D., Wright, H. (2016). Employee engagement trends. Quantum Workplace. 53p.

Hansez, I., \& Chmiel, N. (2010). Safety behavior: Job demands, job resources, and perceived management commitment to safety. Journal of Occupational Health Psychology, 15, 267-278.

Hayes, A. F. (2013). Introduction to mediation, moderation, and conditional process analysis: $A$ regression-based approach. New York, NY: The Guilford Press.

Hornung, S., Rousseau, D. M., Glaser, J., Angerer, P., \& Weigl, M. (2010). Beyond top-down and bottom-up work redesign: Customizing job content through idiosyncratic deals. Journal of Organizational Behavior, 31, 187-215. https://doi.org/ $10.1002 /$ job. 625

Hobfoll, S. E. (1989). Conservation of resources: A new attempt at conceptualizing stress. American Psychologist, 44, 513-524.

Huang, J., Wang, Y., \& You, X. (2016). The job demands-resources model and job burnout: The mediating role of personal resources. Current Psychology, 32, 562-569.

Jimmieson, N. L., Terry, D. J., \& Callan, V. J. (2004). A longitudinal study of employee adaptation to organizational change: The role of change-related information and change-related self-efficacy. Journal of Occupational Health Psychology, 9, 11-27.

Kim, N., \& Kang, S.-W. (2017). Older and more engaged: The mediating role of age-linked resources on work engagement. Human Resource Management, 56(5), 731-746. https://doi.org/10.1002/ hrm. 21802

Košč, M., Heftyová, E., Schwarzer, R., \& Jerusalem, M. (1993). Slovakian adaptation of the General Self-Efficacy Scale. Accessible at: http:// userpage.fu-berlin.de/ health/slovak.htm 
Leiter, M. P., \& Maslach, C. (2004). Areas of worklife: A structured approach to organizational predictors of job burnout. In P. L. Perrewe \& D. C. Ganster (Eds.), Emotional and Physiological Processes and Positive Intervention Strategies, Research in Occupational Stress and Well Being (pp. 91-134) Elsevier: Oxford.

LePine, J. A., Podsakoff, N. P., \& Lepine, M. A. (2005). A meta-analytic test of the challenge stressorhindrance stressor framework: An explanation for inconsistent relationships among stressors and performance. Academy of Management Journal, 48(5), 764-775.

Luthans, F., Avey, J. B., Avolio, B. J., Norman, S. M., \& Combs, G. M. (2006). Psychological capital development: Toward a micro-intervention. Journal of Organizational Behavior, 27, 387-393.

Lyons. P. (2008). The crafting of jobs and individual differences. Journal of Business Psychology, 23, 25-36.

Macey, W. H., \& Schneider, B. (2008). The meaning of employee engagement. Industrial and Organizational Psychology, 1, 3-30.

Maslach, C., Jackson, S. E., \& Leiter, M. (1996). Maslach Burnout Inventory: Manual (3rd ed.). Palo Alto, CA: Consulting Psychologists Press.

Nadin, S. J., Waterson, P. E., \& Parker, S. K. (2001). Participation in job redesign: An evaluation of the use of a sociotechnical tool and its impact. Human Factors and Ergonomics in Manufacturing, 11, 53-69.

Näätänen, P., Aro, A., Matthiesen, S., \& Salmela-Aro, K. (2003). Bergen burnout indicator 15. Edita: Helsinki.

Najung, K., Seung-Wan, K. (2017). Older and more engaged: The mediating role of age-linked resources on work engagement. Human Resource Management, 56(5), 731-746.

Nielsen, K., \& Abildgaard, J. S. (2012). The development and validation of a job crafting measure for use with blue-collar workers. Work \& Stress: An International Journal of Work, Health and Organisations, 27(3), 278-297. https://doi.org/ $10.1080 / 02678373.2012 .733543$

Parker, S. K., \& Ohly, S. (2008). Designing motivating jobs. In R. Kanfer, G. Chen, \& R. Pritchard (Eds.) Work motivation: Past, present, and future.

Parker, S. K. (2014). Beyond motivation: Job and work design for development, health, ambidexterity, and more. Annual Review of Psychology, 65, 661-691. https://doi.org/10.1146/annurev-psych010213-115208

Petrou, P., Demerouti, E., Peeters, M. C. W., Schaufeli, W. B., \& Hetland, J. (2012). Crafting a job on a daily basis: Contextual correlates and the link to work engagement. Journal of Organizational Behavior 33, 1120-1141.

Petrou, P., Demerouti, E., \& Schaufeli, W. B. (2015) Job crafting in changing organizations: Antecedents and implications for exhaustion and performance. Journal of Occupational Health Psychology, 20(4), 1-11.

Petrou, P., Demerouti, E., \& Xanthopoulo, D. (2016). Regular versus cutback-related change: The role of employee job crafting in organizational change contexts of different nature. International Journal of Stress Management, 24(1), 62-85. https:// doi.org/10.1037/str0000033

Podsakoff, P. M., MacKenzie, S. B, Lee, J.-I., \& Podsakoff, N. P. (2003). Common method biases in behavioral research: A critical review of the literature. Journal of Applied Psychology, 88(5), 879-903. doi: 10.1037/0021-9101.88.5.879

Preacher, K. J., \& Kelley, K. (2011). Effect size measures for mediation models: Quantitative strategies for communicating indirect effects. Psychological Methods, 16(2), 93-115. doi: 10.1037/ a0022658.

Rudolph, C. W., Katz, I. M., Lavigne, K. N. \& Zacher, H. (2017). Job crafting: A meta-analysis of relationships with individual differences, job characteristics, and work outcomes. Journal of Vocational Behavior, 102, 112-138. https://doi.org/ 10.1016/j.jvb.2017.05.008

Schaufeli, W. B., \& Bakker, A. B. (2004a). Job demands, job resources, and their relationship with burnout and engagement: A multi-sample study. Journal of Organizational Behavior, 25(3), 293315.

Schaufeli, W. B., \& Bakker, A. B. (2004b). Utrecht work engagement scale: Preliminary manual. Occupational Health Psychology Unit. Utrecht: Utrecht University.

Schaufeli, W. B., Bakker, A. B., \& Van Rhenen, W. (2009). How changes in job demands and resources predict burnout, work engagement, and sickness absenteeism. Journal of Organizational Behavior, 30(7), 893-917. https://doi.org/10.1002/ job.595

Schaufeli, W. B., Salanova, M., González-Romá, V., \& Bakker, A. B. (2002). The measurement of engagement and burnout: A two sample confirmatory factor analytic approach. Journal of Happiness Studies, 3(1), 71-92.

Tims, M., \& Bakker, A. B. (2010). Job crafting: Towards a new model of individual job redesign. South African Journal of Industrial Psychology, 36(2), 1-9. https://doi.org/10.4102/sajip.v36i2.841

Tims, M., Bakker, A. B., \& Derks, D. (2012). Development and validation of the job crafting scale. Jour- 
nal of Vocational Behavior, 80(1), 173-186. https:/ /doi.org/10.1016/j.jvb.2011.05.009

Tims, M., Bakker, A. B., \& Derks, D. (2013). The impact of job crafting on job demands, job resources, and well-being. Journal of Occupational Health Psychology, 18(2), 230-40.

Tims, M., Derks, D., \& Bakker, A. B. (2016). Job crafting and its relationship with person-job fit and meaningfulness: A three-wave study. Journal of Vocational Behavior, 92, 44-53. https://doi.org/ 10.1016/j.jvb.2015.11.007

Tornau, K., \& Frese, M. (2015). Construct clean-up in proactivity research: A meta-analysis on the nomological net of work-related proactivity concepts and their incremental validities. Applied Psychology: An International Review, 64, 626-636. https://doi.org/10.1111/apps.12045

Trépanier, S. G., Austin, S., Forest, J., \& Vallerand, R.J. (2014). Linking job demands and resources to burnout and work engagement: Does passion underlie these differential relationships? Motivation and Emotion, 38, 353-366.

Van den Broeck, A., Vansteenkiste, M., De Witte, H., \& Lens, W. (2008). Explaining the relationships between job characteristics, burnout, and engagement: The role of basic psychologi- cal need satisfaction. Work \& Stress, 22(3) 277-294.

Van Hooff, M. L. M., \& Van Hooft, E. A. (2014). Boredom at work: Proximal and distal consequences of affective work-related boredom. Journal of Occupational Health Psychology, 19(3), 348-359. Wrzesniewski, A., \& Dutton, J. E. (2001). Crafting a job: Revisioning employees as active crafters of their work. Academy of Management Review, 26(2), 179-201.

Xanthopoulou, D., Bakker, A. B., Demerouti, E., \& Schaufeli, W. B. (2007). The role of personal resources in the job demands-resources model. International Journal of Stress Management, 14(2), 121-141. https://doi.org/10.1037/1072-5245.14. 2.121

Xanthopoulou, D., Bakker, A. B., Demerouti, E., \& Schaufeli, W. B. (2009). Work engagement and financial returns: A diary study on the role of job and personal resources. Journal of Occupational and Organizational Psychology, 82(1), 183-200. https://doi.org/10.1348/096317908X285633

Zacher, H., Hacker, W., \& Frese, M. (2016). Action regulation across the adult lifespan (ARAL): A metatheory of work and aging. Work, Aging and Retirement, 2(3), 286-306. 